\title{
The conceptual/procedural distinction belongs to strategies, not tasks: A comment on Gabriel et al. (2013)
}

\author{
Thomas J. Faulkenberry* \\ Department of Psychology and Counseling, Tarleton State University, Stephenville, TX, USA \\ *Correspondence: faulkenberry@tarleton.edu \\ Edited by: \\ Korbinian Moeller, Knowledge Media Research Center, Germany
}

Keywords: fractions, conceptual knowledge, procedural knowledge, strategies, mathematics education

\section{A commentary on}

A componential view of children's difficulties in learning fractions

by Gabriel, F., Coché, F., Szucs, D., Carette, V., Rey, B., and Content, A. (2013). Front. Psychol. 4:715. doi: 10.3389/fpsyg.2013.00715

In their recent article, Gabriel et al. (2013) propose that the difficulty experienced by Belgian children in learning fractions stems from the fundamental dichotomy of procedural and conceptual knowledge of fractions. Indeed, the authors are not alone in this conclusion, as the procedural/conceptual knowledge divide has been a focus in several recent studies in numerical cognition (Hallett et al., 2010; Hecht and Vagi, 2012). Like their predecessors, Gabriel et al. adopt the definitions introduced by Rittle-Johnson and Alibali (1999), where conceptual knowledge refers to the understanding of the principles that govern a knowledge domain and procedural knowledge refers to knowledge of specific actions that are used to solve problems. This work stems from a rich foundation in mathematics education regarding the roles of procedural and conceptual knowledge in school-age children's mathematical development (Hiebert, 1986).

The issue I wish to raise in this commentary is not with the conclusions of Gabriel et al. (2013), but rather a general issue concerning the notion of conceptual and procedural tasks in mathematics. One of the difficulties is that a single task can reflect both types of knowledge. Indeed, consider the task of shading a geometric object (such as a square) to reflect a given fraction, say $3 / 4$. This task appears from the outset to reflect conceptual knowledge, specifically since successful completion of the task gives some indication of the participant's knowledge of part-whole relationships in fractions. But, consider the alternative where a child is explicitly taught to perform this shading by first breaking the square into four equal sections, then shading three of the sections. Does this constitute a demonstration of conceptual knowledge? Or, does it reflect the use procedural knowledge? Hallett et al. (2010) would side with procedural knowledge since the procedure was explicitly taught to the child beforehand. Other authors (Hecht and Vagi, 2012; Gabriel et al., 2013) used this task and chose to call it a conceptual task. I would argue that the main question should not be whether the task is procedural or conceptual, but instead whether the employed strategy reflects the use of procedural or conceptual knowledge.

A related issue arises in Figure $3 \mathrm{~d}$ of Gabriel et al. (2013). In this figure, a child has represented the fraction $2 / 6$ by shading two parts of a circle that has been divided into six sections. The problem is that the two shaded sections are much larger than the four non-shaded sections, and as a result, the shaded fraction is actually $1 / 2$. While this is a common error (and is apparently cross-cultural), it raises an important question. Does this child reflect conceptual understanding of fractions? I would argue no, since a conceptual understanding of the part-whole relationship would include the knowledge that the six parts should be equal in size. Of course, others may interpret this differently, and that is fine. My larger point is that it can be argued either way, and as such, the task does not define the knowledge that is used. Rather, it is the strategy used to complete the task that helps us make our conclusions.

Another common example of a task that can reflect both procedural and conceptual knowledge is the magnitude comparison task (e.g., which fraction is larger: $1 / 3$ or $3 / 5$ ?). Both Gabriel et al. (2013) and Hecht and Vagi (2012) termed this a conceptual task, presumably because it reflects the concept of fraction as a number. Indeed, if participants are forming mental representations of the fractions' magnitudes, then I feel that this is likely an accurate description. However, in a study with adults, Faulkenberry and Pierce (2011) found that on approximately $25 \%$ of trials, participants used a strategy known as cross-multiplication, where the size judgement is made by comparing cross-products (numerator of one fraction multiplied by denominator of another). This is a common procedural strategy that is employed in US schools for teaching students how to compare fractions (Boston et al., 2003). More importantly, this procedure allows the participant to arrive at an answer with no sense of the fraction as a number (i.e., no conceptual knowledge). Without explicitly asking participants to describe their solution strategy, it would not have been clear that they were using such a strategy, and by implication, it would have been impossible to know that they were using a procedural strategy on a task that looked conceptual.

From here, it is clear that there is a fundamental inconsistency in the literature. I think the proactive solution to this inconsistency lies in clearly delineating between the notions of conceptual/procedural 
tasks and conceptual/procedural strategies. Simply coining tasks as procedural or conceptual does not appear to be sufficient. Rather, we need some knowledge of a participant's solution strategy to accurately determine which type of knowledge is responsible for the solution. Admittedly, this can be difficult to ascertain, as it requires interviewing participants about their methods of solving problems. While a trial-by-trial report of strategies may be the gold standard in this type of research, such data is timeconsuming to gather. More optimistically, it may be possible to get a decent measure of strategy to simply asking participants post-hoc to simply describe how they solve problems of a given type. At the very least, tasks that are used in studies of conceptual/procedural knowledge should be subjected to at least two rounds of independent ratings of to how they reflect one type of knowledge or the other. This was the approach used in Hallett et al. (2010), and I feel that such data should be minimally required in future studies of this type.

In summary, I believe Gabriel et al. (2013) have conducted an important study in the field of numerical cognition of fractions, particularly from the standpoint that it (1) identifies an important shortcoming of early fraction knowledge that appears to be cross-cultural, and it (2) begins an important dialogue about the methodological issues that we should consider when investigating the nature of conceptual and procedural knowledge in mathematics. We should continue to devote our time to serious investigations of the factors that influence conceptual and procedural knowledge in mathematics. At the same time, we should acknowledge that our current notion of labeling tasks as procedural or conceptual is limited, and that in the future we should investigate whether strategies employed on these tasks better reflect the use of procedural or conceptual knowledge.

\section{REFERENCES}

Boston, M. D., Smith, M. S., and Hillen, A. F. (2003). Building on students' intuitive strategies to make sense of cross multiplication. Math. Teach. Mid. School 9, 150-155.

Faulkenberry, T. J., and Pierce, B. H. (2011). Mental representations in fraction comparison: holistic versus component-based strategies. Exp. Psychol. 58, 480-489. doi: 10.1027/1618-3169/ a000116

Gabriel, F., Coché, F., Szucs, D., Carette, V., Rey, B., and Content, A. (2013). A componential view of children's difficulties in learning fractions. Front. Psychol. 4:715. doi: 10.3389/fpsyg.2013.00715

Hallett, D., Nunes, T., and Bryant, P. (2010). Individual differences in conceptual and procedural knowledge when learning fractions. J. Educ. Psychol. 102, 395-406. doi: 10.1037/a0017486

Hecht, S. A., and Vagi, K. J. (2012). Patterns of strengths and weaknesses in children's knowledge about fractions. J. Exp. Child Psychol. 111, 212-229. doi: 10.1016/j.jecp.2011.08.012

Hiebert, J. E. (1986). Conceptual and Procedural knowledge: The Case of Mathematics. Hillsdale, NJ: Lawrence Erlbaum Associates, Inc.

Rittle-Johnson, B., and Alibali, M. W. (1999). Conceptual and procedural knowledge of mathematics: does one lead to the other? J. Educ. Psychol. 91, 175-189. doi: 10.1037/0022-0663.91.1.175

Received: 11 October 2013; accepted: 15 October 2013; published online: 06 November 2013.

Citation: Faulkenberry TJ (2013) The conceptual/procedural distinction belongs to strategies, not tasks: A comment on Gabriel et al. (2013). Front. Psychol. 4:820. doi: 10.3389/fpsyg.2013.00820

This article was submitted to Developmental Psychology, a section of the journal Frontiers in Psychology.

Copyright (c) 2013 Faulkenberry. This is an openaccess article distributed under the terms of the Creative Commons Attribution License (CC BY). The use, distribution or reproduction in other forums is permitted, provided the original author(s) or licensor are credited and that the original publication in this journal is cited, in accordance with accepted academic practice. No use, distribution or reproduction is permitted which does not comply with these terms. 